MATEC Web of Conferences 19, 01014 (2014)

DOI: $10.1051 /$ matecconf/ 20141901014

(C) Owned by the authors, published by EDP Sciences, 2014

\title{
Low-temperature conversion of low-grade organic raw, part 1 (technical aspects)
}

\author{
Alexander V. Kazakova, Roman B. Tabakaev, Pavel Y. Novoseltsev, and Alexander V. Astafev \\ National Research Tomsk Polytechnic University, 634050 Tomsk, Russia
}

\begin{abstract}
Relevance of the local organic raw using in Russian fuel and energy market was shown. Status of Tomsk region decentralized energy supply was analyzed. Variants of power units on the basis of the low-temperature intracyclic conversion were presented. The results of the design calculation power units were given.
\end{abstract}

\section{Introduction}

The relevance of the use of local low-grade fuels provides correspondence with current trends of the conservation of energy, in particular, the direction of implication in the fuel energy balance of lowgrade fuels and providing of electric and heat energy to areas of decentralized energy supply [1-3]. According to the "Energy Strategy of Russia for the period up to 2030" [1], which aims to maximize efficient use of natural energy resources and potential of energy sector for sustainable economic growth, improving of the quality life of population in country and assistance to strengthening of foreign economic positions, as a priority areas of scientific-and-technological advance in energy sector of direction "Renewable energy sources and local fuels" are highlighted as follows:

- development of the technologies of use renewable energy sources, as well as cross functional energy complexes for autonomous power supply of consumers in areas, which not connected to the networks of centralized power supply;

- expansion of production and use of new types of fuel derived from various types of biomass.

Is assumed [1] that by 2030 in the Central, Southern, Siberian and Far Eastern federal districts the role of the use of local energy sources and production of energy based on them in remote and isolated areas will increase. Proportion of heat, produced by cogeneration plants in district heating systems, will be reduced from 43 (in 2005) to 35 percent. Gas turbine installations at cogeneration plants and autonomous heat supply installations should occupy this niche. Low-rise buildings, tend to, should be provided by individual heat generators. To achieve these purposes requires modernization and development of the systems of decentralized heat supply with using of high efficiency condensation gas and coal-fired boilers, cogeneration, geothermal, heat pump, and other installations, as well as automated individual heat generators of new generation for combustion of different fuels.

One of the main problems [1] in the regional energy policy is the insufficient development of low power engineering and low implication into the energy balances of the local sources of energy regional and local significance, the solution of which involves maximizing of the economically efficient use of local fuel and energy resources, the development of economically efficient decentralized and individual systems of heat supply. For these purposes, is assumed:

\footnotetext{
${ }^{a}$ Corresponding author: kazakov@tpu.ru
} 


\section{MATEC Web of Conferences}

- stimulating of the use of local fuel and energy resources (renewable energy, local types of fuel, waste, etc.) and their subsequent involvement in the regional fuel and energy balances;

- optimization of regional heat supply systems based on economically efficient combination of centralized and decentralized heat supply;

- bringing of the proportion of local energy sources in the regional fuel and energy balances to 20 percent;

- formation of a stable energy supply system of remote and isolated areas on the basis of the extended effective use of local energy resources;

- formation of regional energy systems based on the economically efficient combination of the use of local and imported sources of energy.

According to the "Energy Strategy of the Tomsk region for the period up to 2020" [2], the total resources of brown coals in the Tomsk region are 75.7 billion tons or $5 \%$ of the volume of explored resources of brown coals in Russia. Fields of brown coals may be the basis for energy raw material and raw material for reception of chemical substances. Predicted resources are constituted 3.6 billion tons only in Talovskoye field. Tomsk region ranks second in Russia, let have of the Tyumen on reserves of peat. On its territory were detected and taken into account of 1505 fields of peat with a total area in borders of the industrial reservoirs of 7.7 million hectares wit peat reserves of 29 billion tons. Geological and economic study of peat resources is weak. A detailed study fields only 4 with reserves of 570 million tons (less than $3 \%$ of peat resources of the region). Potential energy resources of the forests of Tomsk region are high. Timber reserves evaluated at 2.7 billion $\mathrm{m}^{3}$, of which 737.7 million $\mathrm{m}^{3}$ in coniferous forests. The annual growth of timber is 27.4 million $\mathrm{m}^{3}$, and the volume of annual produced fire woods only in the process of forest care and at the expense of sanitary cuttings may amount to 2 million $\mathrm{m}^{3}$ of timber.

Fuel and energy complex is the basis of the Tomsk region economic and the most important area of industrial activity, which determines the standard of living of the population, so in priorities of the fuel and energy complex, in particular, follows [2]:

- improving of the balance of boiler and furnace fuels due to the implication of local resources (peat, brown coal and wood);

- market expansion of the sale of local fuel and energy resources and reducing of the volume of imported fuel.

Solving the problem of increasing the economic efficiency and capacity utilization of the untraditional renewable energy sources on the basis of the perspective technologies of intracyclic gasification in power units is made the actual problem of scientific research. According to [3], in the Tomsk region are situated 21 settlements with a population of 33.7 thousand persons, energy supply of which is comes from diesel power plants (DPP), founded in municipally ownership of the administrations of districts and transferred to the service of municipal utilities. The entire park of diesel generator installations in municipal DPP had more than 100 machines with a total installed power of $50 \mathrm{MW}$. Question of the implication of local fuels in the fuel and energy balance is put quite legitimate.

\section{Main part}

By now we know quite a lot of works on the complex processing of local low-grade fuels [4-7]. So, at the department of steam generation build and steam generator installations (SGB and SGI) in Tomsk Polytechnic University are carried a research on low-temperature catalytic processing of low-grade fuels, such as sawdust, peat, brown coal [7-9]. As a result of the research, the data that formed the basis for the design of power units [9-11], which are realized the process of low-temperature intracyclic conversion of low-grade fuels with production of heat and electric energy: the individual heat supply unit (Figure 1); the individual heat and power supply unit (Figure 2); the unit of solid fuels gasification - gasifier (Figure 3). 


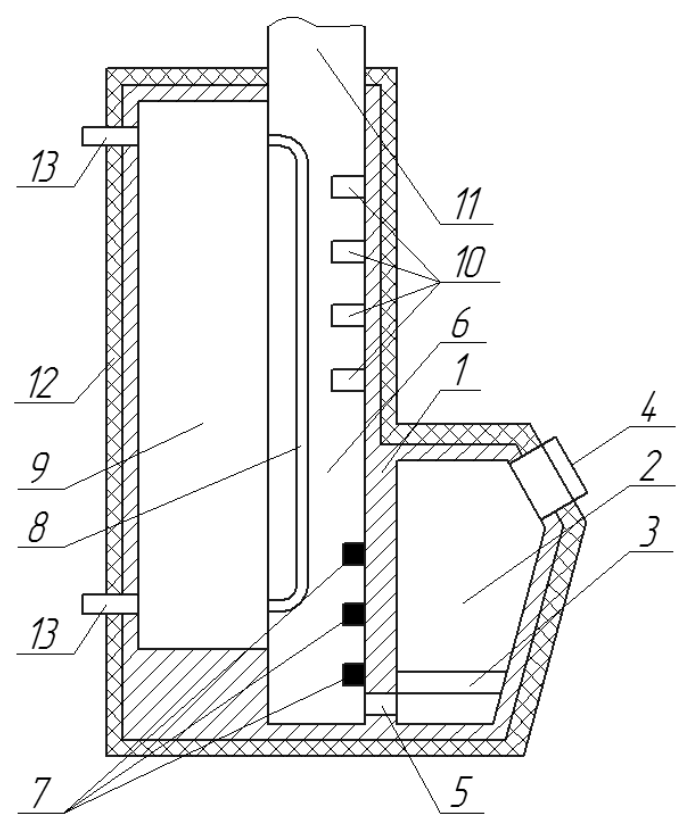

Figure 1. Individual heat supply unit [10]: 1 - body; 2 - fuel bunker; 3 - grate; 4 - cargo hatch; 5 - channel for supplying of synthesis gas; 6 - gas-fired furnace; 7,8 - the first and the second stages of oxidation; 9 - heat exchanger; 10 - the third stage of the system of oxidation; 11 - output of flue exhaust; 12 - heat insulation; 13 - connection with the heating system.

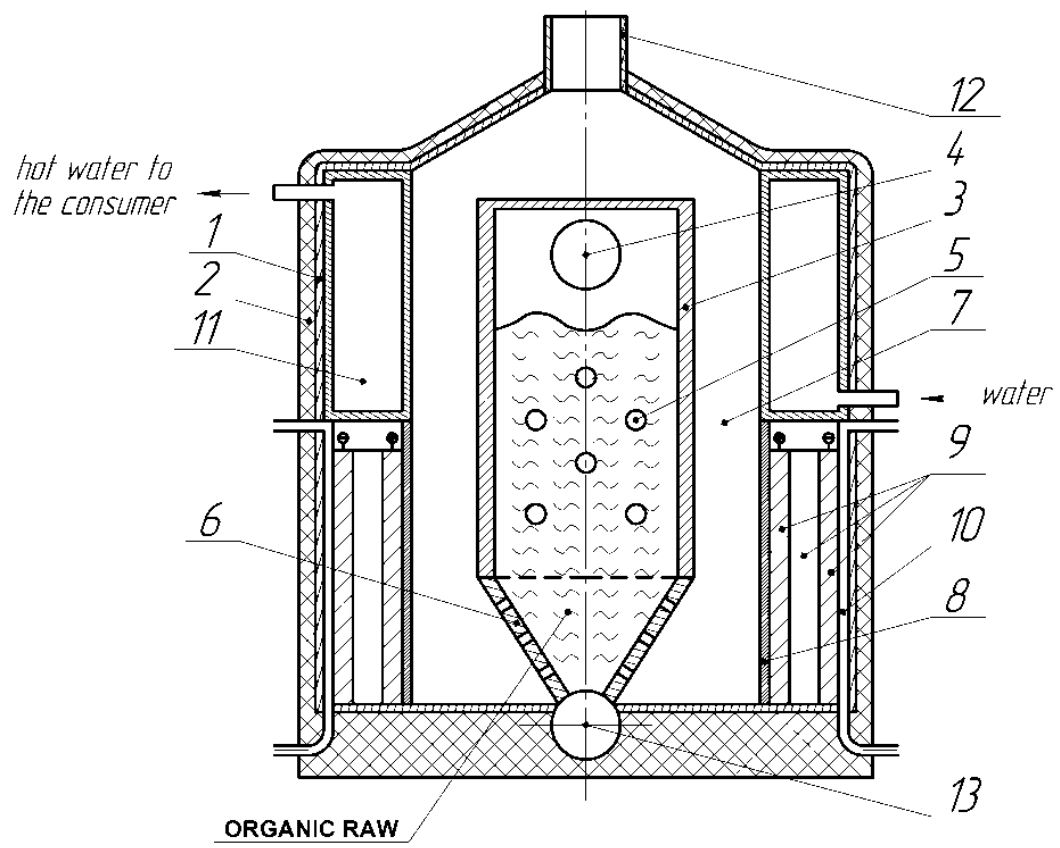

Figure 2. Individual heat and power supply unit [9]: 1 - body; 2 - heat insulation; 3 - pyrolysis reactor; 4 - the fuel supply; 5 - input of gasifying agent; 6 - grate; 7 - combustion chamber; 8 - the catalyst; 9 - fuel cell; 10 - air chamber; 11 - the heat exchanger; 12 - smokestack; 13 - system of ash handling. 


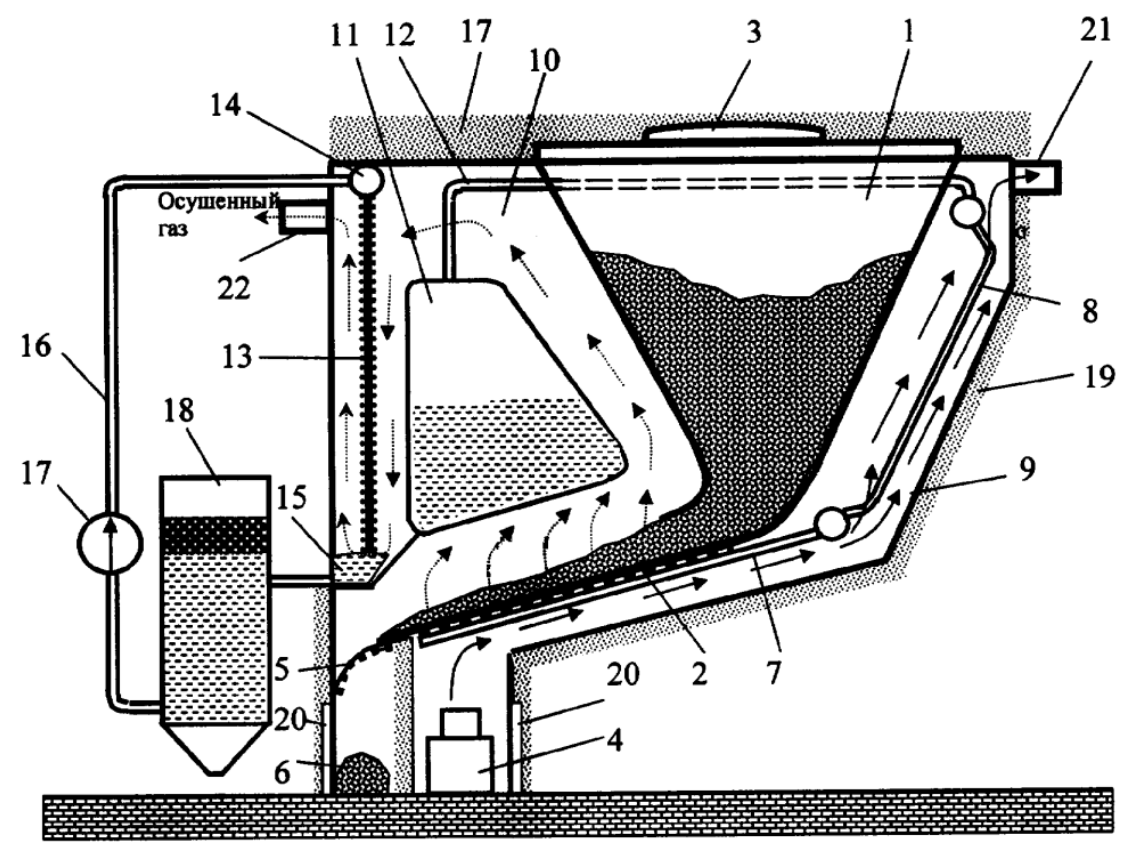

Figure 3. Unit of solid fuels gasification (gasifier)[11]: 1 - fuel bunker; 2 - working surface; 3 - charging port; 4 - gas burner; 5 - grate; 6 - recipient of ash; 7 - steam-supply tubes; 8 - superheater; 9 - channel of the movement of flue gases; 10 - gas chamber; 11 - water bunker; 12 - steam outlet tubes; 13 - cooling screen; 14 - collector; 15 - water seal; 16 - pipeline; 17 - pump; 18 - container for water; 19 - heat insulation; 20 - inspection holes; 21 - pipe header for exhausting of fire gases; 22 -pipe header for output of dry gas.

The purpose of the present work is a theoretical substantiation with the use of methodological tools of the evaluation of efficiency of the development of innovative technologies by energy use of low-grade fuels in the power engineering on the basis of the low-temperature intracyclic conversion.

The main idea of the explored technology of intracyclic conversion is a low-temperature intracyclic thermal processing of the local low-grade fuels of high humidity on pyrolysis reactor and reception of hydrogen synthesis gas by applying a high-efficiency technology of thermal-stream catalytic conversion of the carbon of fuels, the main advantages of which are as follows:

- accessible local raw materials is fuel;

- recycling products may represent by the source material for further use;

- process management at low temperatures allows to reduce the investment and reduces environmental pollution;

- available substance is catalyst;

- possibility of partial or complete decentralization of energy supply.

All three units of intracyclic conversion, developed at the department of SGB and SGI, based on low-temperature fuel processing. Local raw materials used by fuel (brown coal, peat, sawdust), recycling products are the source material for further use; the process is carried out at low temperatures (up to $400{ }^{\circ} \mathrm{C}$ ). The units are designed for heating, hot water supply and generation of electric power for objects of small-scale generation and individual consumers. The units operate on natural draft, which is created by the smokestack and the units themselves. Circulation of heat carrier is natural and carried out due to by difference of densities between incoming and leaving water. Engineering design was performed for units operating on sawdust, the results of which are discharge characteristic and the basic geometric sizes of the devices (Table 1-3). 
Table 1. Results of the Individual heat supply unit calculate.

\begin{tabular}{|l|c|c|c|}
\hline \multirow{2}{*}{\multicolumn{1}{|c|}{ Parameters }} & \multicolumn{3}{c|}{ Power, $\mathbf{k W}$} \\
\cline { 2 - 4 } & $\mathbf{1 0 0}$ & $\mathbf{5 5}$ & $\mathbf{4}$ \\
\hline Gas consumption, $\mathrm{m}^{3} / \mathrm{s}$ & 0.006 & 0.0032 & 0.0002 \\
\hline Total fuel consumption, $\mathrm{kg} / \mathrm{s}$ & 0.007 & 0.0034 & 0.00023 \\
\hline Overall dimensions, $\mathrm{L} \times \mathrm{W} \times \mathrm{H}, \mathrm{m}$ & $3 \times 1 \times 3$ & $3 \times 1 \times 3$ & $3 \times 1 \times 0.8$ \\
\hline Amount of heat exchange tubes, $\mathrm{pcs}$. & 66 & 50 & 10 \\
\hline
\end{tabular}

Table 2. Results of the Individual heat and power supply unit calculate.

\begin{tabular}{|l|c|c|c|}
\hline \multirow{2}{*}{\multicolumn{1}{|c|}{ Parameters }} & \multicolumn{3}{|c|}{ Power, kW } \\
\cline { 2 - 4 } & $\mathbf{1 0 0}$ & $\mathbf{5 0}$ & $\mathbf{3}$ \\
\hline Gas consumption, $\mathrm{m}^{3} / \mathrm{s}$ & 0.006 & 0.003 & 0.0002 \\
\hline Total fuel consumption, $\mathrm{kg} / \mathrm{s}$ & 0.007 & 0.0032 & 0.0002 \\
\hline Height of the carbon electrode, $\mathrm{m}$ & 1 & 1 & 1 \\
\hline Outer diameter of the water tank, $\mathrm{m}$ & 1.08 & 1.08 & 1.08 \\
\hline Outer diameter of the fuel bunker, $\mathrm{m}$ & 1.08 & 1.08 & 1.08 \\
\hline Height of installation, $\mathrm{m}$ & 3 & 3 & 3 \\
\hline Amount of electrodes, pcs & 6 & 3 & 1 \\
\hline Amount of heat transfer plates, $\mathrm{pcs}$ & 246 & 142 & 91 \\
\hline
\end{tabular}

Table 3. Results of the gasifier calculate.

\begin{tabular}{|l|c|c|c|}
\hline \multirow{2}{*}{ Parameters } & \multicolumn{3}{|c|}{ Power, $\mathbf{k W}$} \\
\cline { 2 - 4 } & $\mathbf{1 0 0}$ & $\mathbf{5 0}$ & $\mathbf{3}$ \\
\hline Gas consumption, $\mathrm{m}^{3} / \mathrm{s}$ & 0.006 & 0.003 & 0.0002 \\
\hline Total fuel consumption, $\mathrm{kg} / \mathrm{s}$ & 0.007 & 0.0032 & 0.0002 \\
\hline Overall dimensions, $\mathrm{W} \times \mathrm{H}, \mathrm{m}$ & $1 \times 2.45$ & $1 \times 2.45$ & $1 \times 2.45$ \\
\hline Length of the lower part of gasifier, $\mathrm{m}$ & 0.5 & 0.5 & 0.5 \\
\hline Length the upper part of gasifier, $\mathrm{m}$ & 5.4 & 5.4 & 5.4 \\
\hline Amount of heat exchange tubes, $\mathrm{pcs}$. & 24 & 10 & 3 \\
\hline
\end{tabular}

\section{Conclusions}

Calculation of the economic effect from substitution of the park of diesel power plants (DPP) under the units is made on the basis of above-stated results. A comparison of the annual costs of the maintaining of DPP and the benefits, in monetary terms, which can be obtained from the use of the units will be the economic result, which is expected from their introduction. In according to the above the main tasks for evaluation of the effective introduction of power units intracyclic conversion of low-grade fuels are follows:

- definitionof the cost of production and operation of the units;

- definitionof the budgetary efficiency of substitution DPP on the units;

- Sensitivity analysis based on scripts of the development of project;

- Definition of the expected integral effect.

The reported study was partially supported by the Ministry of education and science of The Russian Federation (Government Order No. 13.948.2014/K).

\section{References}

1. Order of the Russian Federation Government № 1715-r "Energy Strategy of Russia for the period up to 2030" (November 13, 2009) [in Russian] 


\section{MATEC Web of Conferences}

2. Supplement to the Decision of the Tomsk region State Duma № 1008 "Energy Strategy of the Tomsk region for the period up to 2020" (February 28, 2008) [in Russian]

3. O. A. Surzhikova, Siberian Journal of Science 4, 103 (2012) [in Russian]

4. A. Samylin, M. Yashin, LesPromInform 59, 78 (2009) [in Russian]

5. A. D. Simonov, I. A. Fedorov, Y. V. Dubinin, N. A. Yazykov, V. A. Yakovlev, V. N. Parmon, Catalysis in Industry 5, 42 (2013)

6. J. Zhang, R. Wu, G. Zhang, J. Yu, C. Yao, Y. Wang, S. Gao, G. Xu, Energy and fuels 27, 1951 (2013)

7. A. S. Zavorin, A. V. Kazakov, A.A. Makeev, S.V. Podorov, Thermal Engineering 57, 77 (2010)

8. A.A. Makeev, A. V. Kazakov, Proceedings of International Scientific and Technical Seminar "Energy: efficiency, reliability, safety", 1998, p. 105-106 [in Russian]

9. A.V. Kazakov, A.S. Zavorin, P.Y. Novoseltsev, R. B. Tabakaev, Bulletin of the Tomsk Polytechnic University 324, 54 (2014) [in Russian]

10. A. S. Zavorin, A.V. Kazakov, R. B. Tabakaev, RF Patent No. 2498 166, Byull. Izobret., No. 31 (2013)

11. A. S. Zavorin, A.A. Makeev, A. V. Kazakov, S.V. Podorov, RF Patent No. 2337 941, Byull. Izobret., No. 31 (2008) 